\title{
Bromate Removal from Water Using Doped Iron Nanoparticles on Multiwalled Carbon Nanotubes (CNTS)
}

\author{
Aasem Zeino, ${ }^{1}$ Abdalla Abulkibash, ${ }^{1}$ Mazen Khaled, ${ }^{1}$ and Muataz Atieh ${ }^{2}$ \\ ${ }^{1}$ Chemistry Department, King Fahd University of Petroleum and Minerals, Dhahran 31261, Saudi Arabia \\ ${ }^{2}$ Chemical Engineering Department, King Fahd University of Petroleum and Minerals, Dhahran 31261, Saudi Arabia \\ Correspondence should be addressed to Muataz Atieh; motazali@hotmail.com
}

Received 15 September 2013; Revised 28 November 2013; Accepted 17 December 2013; Published 6 February 2014

Academic Editor: Godwin Ayoko

Copyright (C) 2014 Aasem Zeino et al. This is an open access article distributed under the Creative Commons Attribution License, which permits unrestricted use, distribution, and reproduction in any medium, provided the original work is properly cited.

\begin{abstract}
The raw carbon nanotubes (CNTs) were prepared by the floating catalyst chemical vapor deposition method. The raw carbon nanotubes were functionalized, impregnated with iron nanoparticles, and characterized using high resolution transmission electron microscopy (HRTEM), scanning electron microscopy with energy dispersive spectroscopy (SEM-EDS), Fourier transform infrared spectroscopy (FTIR), Differential Scanning Calorimetry (DSC), and thermogravimetric analysis (TGA). The three types of these multiwalled carbon nanotubes were applied as adsorbents for the removal of bromate from drinking water. The effects of the $\mathrm{pH}$, the concentration of $\mathrm{BrO}_{3}{ }^{-}$anion, the adsorbent dose, the contact time, and the coanions on the adsorption process have been investigated. The results concluded that the highest adsorption capacities were 0.3460 and $0.3220 \mathrm{mg} / \mathrm{g}$ through using CNTs-Fe and raw CNTs, respectively, at the same conditions. The results showed that the CNTs-Fe gives higher adsorption capacity compared with the raw CNTs and the functionalized CNTs. The presence of nitrate $\left(\mathrm{NO}_{3}{ }^{-}\right)$in the solution decreases the adsorption capacity of all CNTs compared with chloride $\left(\mathrm{Cl}^{-}\right)$associated with $\mathrm{pH}$ adjustment caused by nitric acid or hydrochloric acid, respectively. However, the adsorption of all MWNCTs types increases as the $\mathrm{pH}$ of solution decreases.
\end{abstract}

\section{Introduction}

Bromate $\left(\mathrm{BrO}_{3}{ }^{-}\right.$anion) is a disinfection by-product (DBP) which is formed during the ozonation process of bromide containing waters. Bromate is classified as a "Group 2B" species which is considered as a possible human carcinogen by the International Agency of Research on Cancer (IARC) [1]. Bromate concentration is regulated in drinking water and the maximum contaminant level (MCL) is set at a level of $10 \mu \mathrm{g} / \mathrm{L}$ by United States Environmental Protection Agency (USEPA) [2] and the World Health Organization (WHO) [3]. However, the USEPA has considered a concentration of $0.05 \mu \mathrm{g} / \mathrm{L}$ of bromate to be responsible for a ratio of 1 in 1,000,000 cancer risk and in 2008 the California Office of Environmental Health Hazard Assessment a level of $0.1 \mu \mathrm{g} / \mathrm{L}$ $\mathrm{BrO}_{3}{ }^{-}$anion.

The formation of $\mathrm{BrO}_{3}{ }^{-}$anion occurs during the ozonation of water containing bromide ion $\left(\mathrm{Br}^{-}\right)$. The radical hydroxyl mechanism starts when ozone and/or hydroxyl radical oxidizes $\mathrm{Br}^{-}$into hypobromous acid $(\mathrm{HOBr})$ and/or hypobromite radical $\left(\mathrm{BrO}^{\circ}\right)$ or even the bromide radical $\left(\mathrm{Br}^{\circ}\right)$. Then, further oxidation of $\mathrm{HOBr}$ and $\mathrm{BrO}^{\circ}$ by ozone or hydroxyl radicals forms $\mathrm{BrO}_{3}{ }^{-}$anion [4-7]. Bromate ion was noticed in the concentrated sodium hypochlorite $(\mathrm{NaOCl})$ solutions used for drinking water disinfection as a contaminant [8].

Three approaches have been applied to control $\mathrm{BrO}_{3}{ }^{-}$ anion in water: (1) removal of the bromate precursors before ozonation such as bromide and natural organic matters (NOM), (2) control of bromate formation during ozonation process by controlling the operating conditions, and (3) the removal of bromate after formation called posttreatment [9]. All approaches can be applied in real drinking water industries depending on the operational conditions. Optimization of the conditions of ozonation proved to introduce a good control for the formation of $\mathrm{BrO}_{3}{ }^{-}$anion. For example, lowering the $\mathrm{pH}$ reduces the formation of $\mathrm{BrO}_{3}{ }^{-}$anion, while increasing ozone concentration and the contact time will 
increase the formation of $\mathrm{BrO}_{3}{ }^{-}$anion. However, decreasing the $\mathrm{pH}$ and the addition of ammonia which reacts with $\mathrm{HOBr}$ will reduce the formation of $\mathrm{BrO}_{3}{ }^{-}$anion [10].

Several techniques have been suggested for the removal of $\mathrm{BrO}_{3}{ }^{-}$anion from drinking water after ozonation. Those techniques include filtration, membrane bioreaction, photocatalytic decomposition, reduction reactions, granular activated carbon adsorption, biological reduction, and reduction by zero valent iron [11-16]. Many researchers have studied the adsorption of $\mathrm{BrO}_{3}{ }^{-}$anion by granular and powdered activated carbon filters. The results of bench and pilot scale column tests showed good efficiency in the removal of bromate by granular activated carbon (GAC) [15]. The proposed mechanism of $\mathrm{BrO}_{3}{ }^{-}$anion removal by activated carbon includes adsorption, reduction to hypobromite $\left(\mathrm{OBr}^{-}\right)$, and then reduction to bromide $\left(\mathrm{Br}^{-}\right)$on the activated carbon surface as indicated in the below reactions (R-1) (R-2) [14, 17]. The presence of coanions in water will affect negatively on GAC adsorption capacity:

$$
\begin{gathered}
\equiv \mathrm{C}+\mathrm{BrO}_{3}{ }^{-} \text {anion anion } \longrightarrow \equiv \mathrm{CO}_{2}+\mathrm{BrO}^{-} \\
\equiv \mathrm{C}+2 \mathrm{BrO}^{-} \longrightarrow \equiv \mathrm{CO}_{2}+2 \mathrm{Br}^{-}
\end{gathered}
$$

In recent years, treatment of drinking water has become increasingly difficult. The consequences of industrialization and urbanization resulted in the discharge of number of toxic chemicals of anthropogenic origin into natural surface water bodies. Toxic contaminants such as heavy metals, persistent organics, and endocrine disruptors discharged into surface waters eventually appear in water treatment plants. Presence of toxic contaminants in the source water leaves a deleterious impact on water treatment plants. The treatment efficiency is either reduced or they escape the treatment simply because conventional water treatment plants are not designed to handle them. It is important to realize drinking water treatment has taken a new dimension especially in developed nations, where the treatment plants have to accommodate the additional needs for the removal of complex chemical contaminants originating from anthropogenic sources and, at the same time, safeguard drinking water assets from the risk of being attacked by biothreat agents. Under these circumstances relying solely on technological improvements, while retaining same treatment philosophy, that is, having central treatment facility, may not be sufficient.

The most common adsorbents such as activated carbon for removal of lead [18], carbonate minerals for lead and copper removal [19], activated alumina for arsenic removal $[20,21]$ and persistent organics (e.g., perfluorochemicals (PFC's)) [22], and zeolites for lead removal [18] are successfully used in treatment systems as backed bed filter. Nowadays, nanotechnology has introduced different types of nanomaterials to water industry that can have promising outcomes. Nanosorbents such as CNTs, polymeric materials (e.g., dendrimers), and zeolites have exceptional adsorption properties and are applied for removal of heavy metals, organics, and biological impurities [23]. CNTs in particular received special attention for their exceptional water treatment capabilities and proved to work effective against chemical contaminants. CNTs, as an adsorbent media, are
TABLE 1: Main physical properties of carbon nanotubes samples.

\begin{tabular}{lccc}
\hline Property & Raw CNTS & $\begin{array}{c}\text { Functionalized } \\
\text { CNTS }\end{array}$ & CNTS-Fe 1\% \\
\hline Purity $(\%)$ & $>95$ & $>95$ & $>95$ \\
Surface area, $\left(\mathrm{m}^{2} / \mathrm{g}\right)$ & 233 & NA & NA \\
$\mathrm{pH}_{\text {pzc }}$ & 6.6 & 3.1 & NA \\
Outer diameter $(\mathrm{nm})$ & $20-30$ & $20-30$ & $20-30$ \\
Inside diameter $(\mathrm{nm})$ & $3-5$ & $3-5$ & $3-5$ \\
Length $(\mu \mathrm{m})$ & $10-30$ & $10-30$ & $10-30$ \\
\hline
\end{tabular}

able to remove a wide range of contaminant heavy metals such as $\mathrm{Cr}^{3+}$ [24], $\mathrm{Pb}^{2+}$ [25], and $\mathrm{Zn}^{2+}$ [26], metalloids such as arsenic compounds [27], and organics such as polycyclic aromatic organic compounds (PAH) [28-30] and atrazine [31]. Adsorption of metal contaminants and organics on CNTs is widely studied and extensively reviewed [26], but the sorption of other contamination such bromate using different types of chemically modified and impetrated CNTs needs to be understood in greater detail. In this paper, the effect of raw CNTs, Carboxylated CNTs, and impregnated CNTs on the removal of bromate contaminants were investigated.

\section{Materials and Methods}

2.1. Chemicals. All chemicals were of analytical reagent grade and used as received without pretreatment unless otherwise specified. Potassium bromate, nitric acid, iron (III) nitrate, hydrochloric acid, and absolute ethanol were obtained from Sigma-Aldrich company. All chemical stock solutions and water usages were done using distilled-deionized water (DDW). $\mathrm{BrO}_{3}{ }^{-}$anion solutions with different initial concentrations were prepared by diluting the stock solution by appropriate proportions. The stock solutions were kept cooled $\left(25 \pm 2^{\circ} \mathrm{C}\right)$ and capped in a dark location.

\subsection{Synthesis of Adsorbents}

2.2.1. Raw CNTs. Raw CNTs were synthesized by the floating catalyst chemical vapor deposition (FC-CVD) reactor. The experimental conditions employed including the reactor type, the chemicals, the catalyst, the temperature, and other conditions were similar to those reported elsewhere [32]. The produced CNTs were characterized by the following techniques: IR, SEM, EDS, and TGA-DSC and their basic physical properties are presented in Table 1.

2.2.2. Functionalized CNTs. The functionalized or oxidized CNTs were prepared by oxidizing the raw CNTs by nitric acid [33]. The oxidation process illustrated in Figure 1 usually removes the metallic catalysis from CNTs by dissolution which was used during the synthesis in FC-CVD reactor, enhances the openings of the tube caps, and results in the formation of side-wall holes. This procedure minimizes the shortening of the tubes and the chemical modification will be limited mostly to the tube caps and to the side-walls of the defected sites. 

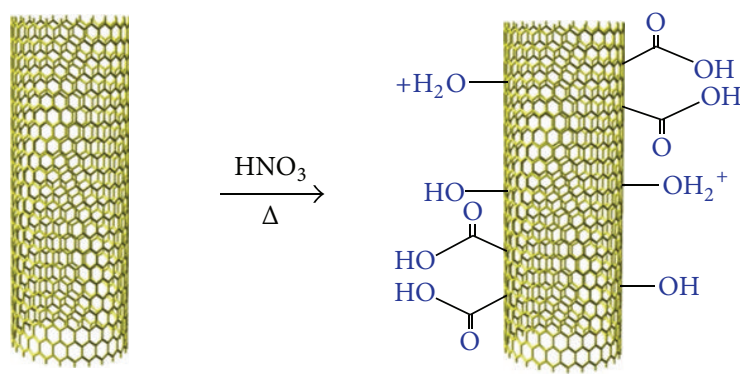

CNT oxidation

FIGURE 1: Chemical functionalization of CNTs through using chemical thermal oxidation.

2.2.3. Iron Impregnated CNTs. The CNTs/iron composite of $1 \%$ as $\mathrm{Fe}$ was prepared by dissolving $0.2164 \mathrm{~g}$ of pure ferric nitrate $\left[\mathrm{Fe}\left(\mathrm{NO}_{3}\right)_{3} \cdot 9 \mathrm{H}_{2} \mathrm{O}\right.$ ] in $250 \mathrm{~mL}$ of absolute ethanol. An amount of $2.970 \mathrm{~g}$ of functionalized CNTs was also dissolved in the $250 \mathrm{~mL}$ of absolute ethanol to give $1 \% \mathrm{Fe}$ content in the resulting mixture. The two solutions were mixed and sonicated for 1 hour in a bath sonicator at room temperature.

2.3. Characterization Methods. Different techniques were utilized to identify the properties of each of the prepared adsorbents. The size and morphology of the three adsorbents were characterized using a field emission scanning electron microscope (SEM; FEI Nova Nano SEM-600) and high resolution transmission electron microscope (HRTEM). Functional groups were characterized using Fourier transform infrared spectroscopy (FT-IR; Thermo Nicolet 6700 ) using $\mathrm{KBr}$ pellet technique. Chemical composition was characterized using energy dispersive spectroscopy (EDS). The decomposition behavior of CNTs types was studied using thermogravimetric analysis (TGA; TA Instruments SDT Q600).

2.4. Preparing the Stock Solution. A standard stock solution of $100 \mathrm{mg} / \mathrm{L} \mathrm{BrO}_{3}{ }^{-}$anion was prepared by dissolving the required mass of the reagent grade $\mathrm{KBrO}_{3}$ (MW: $167.00 \mathrm{~g} / \mathrm{mol}$ ) in DDW. Solutions of different concentrations of $\mathrm{BrO}_{3}{ }^{-}$anion were prepared by dilution and stored in capped flasks in a dark area. Ion chromatograph (IC; Dionex ICS 2000) was used to determine the exact concentrations of the prepared solutions by following Dionex analytical procedure with a detection limit of $1 \mu \mathrm{g} / \mathrm{L}$ (Dionex, 154).

2.5. Batch Adsorption Experiments. Batch mode adsorption experiments were performed using the univariant method using a volume of $50 \mathrm{~mL}$ of $\mathrm{BrO}_{3}{ }^{-}$anion solution in each run. The parameters studied include the $\mathrm{pH}$ of the solution, the adsorbent dosage, the contact time, and the initial concentration of $\mathrm{BrO}_{3}{ }^{-}$anion. The initial $\mathrm{pH}$ of each solution was adjusted using solutions of $0.1 \mathrm{M} \mathrm{NaOH}$ or $0.1 \mathrm{M} \mathrm{HCl}$. The effect of each parameter on the adsorption performance was studied as detailed in the results section. The flasks were covered and mounted on the mechanical rotary shaker (MPI Lab Shaker) and shaken at different times starting from 1 to $48 \mathrm{~h}$. The agitation speed was fixed at $150 \mathrm{rpm}$ in all of the experiments which were carried out at room temperature $\left(25 \pm 2^{\circ} \mathrm{C}\right) . \mathrm{BrO}_{3}{ }^{-}$anion was tested twice, first after $\mathrm{pH}$ adjustment $\left(C_{i}\right)$ and second after shaking, adsorption, and filtration $\left(C_{f}\right)$. Finally, each solution was filtered through a milli bore $0.45 \mu \mathrm{m}$ filtration membrane using a vacuum pump and the adsorption capacities were calculated. The applied equations for the removal percentage of bromated and adsorption capacities are outlined in (2-1), where $\left(C_{i}\right)$ is the initial concentration of $\mathrm{BrO}_{3}{ }^{-}$anion after $\mathrm{pH}$ adjustment and filtration in $\mathrm{mg} / \mathrm{L},\left(C_{f}\right)$ is the final $\mathrm{BrO}_{3}{ }^{-}$ anion concentration after adsorption and filtration in $\mathrm{mg} / \mathrm{L}$, $(V)$ is the volume of solution in liters, $\left(M_{s}\right)$ and is the amount of adsorbent in g:

$$
\begin{gathered}
\text { \%removal }=\frac{C_{i}-C_{f}}{C_{i}} \times 100, \\
\text { Adsorption Capacity } q_{e}\left(\frac{\mathrm{mg}}{\mathrm{g}}\right)=\frac{C_{i}-C_{f}}{M_{s}} \times V .
\end{gathered}
$$

\section{Results and Discussion}

3.1. Characterization of Carbon Nanotubes. The raw CNTs, the functionalized CNTs, and the CNTs-Fe $1 \%$ were characterized using different techniques. The morphologies of these samples were obtained by SEM (Figure 2), where (a), (b), and (c) in this figure show the SEM images of the low and high magnifications of the three CNTs. There is no clear-cut morphological difference between the first two samples, while the CNTs-Fe sample has metal clusters of iron composites circled in Figure 2(c) by the yellow box.

Figure 3(a) shows the high resolution transmission electron microscope (HRTEM) images of raw carbon nanotubes. It is a highly ordered crystalline structure of carbon nanotubes (CNTs) with a diameter range of $10-30 \mathrm{~nm}$. Figure 3(b) shows the TEM images of CNTs impregnated with iron nanoparticles via wet impregnation methods. The diameter of the Fe nanoparticles ranges from 1 to $2 \mathrm{~nm}$ with spherical shape and homogeneous distribution.

FTIR measurements were performed to confirm the formation of new functional groups such as hydroxyl and carboxylic groups on the functionalized CNTs which presented in a previous work [33]. Figure 4 shows the FTIR spectrum of the functionalized CNTs where a broad peak appears at $\sim 3428 \mathrm{~cm}^{-1}$. This peak is characteristic of the stretching of the hydroxyl groups $\mathrm{C}-\mathrm{OH}$ and the carboxylic groups $\mathrm{O}=\mathrm{C}-\mathrm{OH}$. However, such a peak does not exist in the case of the raw CNTs spectrum. The peaks observed on the functionalized CNTs at 1634 and $1460 \mathrm{~cm}^{-1}$ can be attributed to the carboxylate anion stretching mode of the carboxylic groups formed due to the oxidation of surface carbon atoms by nitric acid. The peak observed at $\sim 2358 \mathrm{~cm}^{-1}$ can be associated with the $\mathrm{O}-\mathrm{H}$ stretching from strongly hydrogen bonded $-\mathrm{COOH}$ groups.

Energy dispersive spectroscopy (EDS) analysis was carried out in an attempt to semiquantitatively identify the elemental contents of the used CNTs, especially for trace amounts of impregnated metals and catalysts used during 

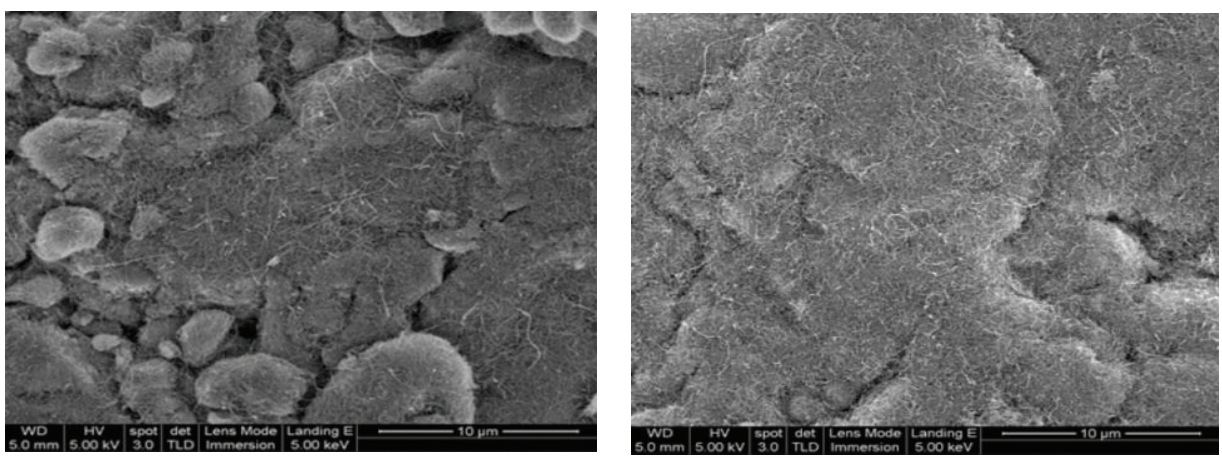

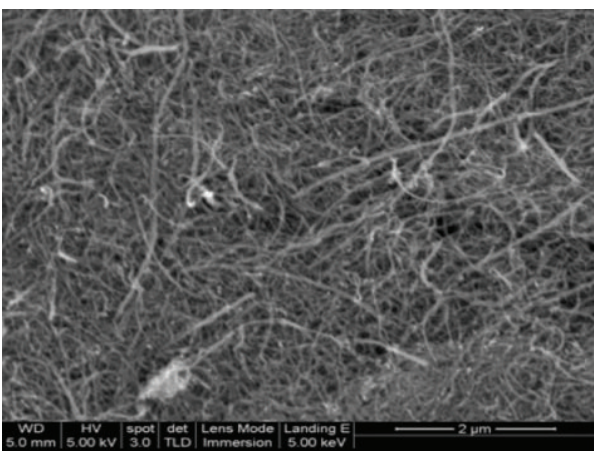

(a)

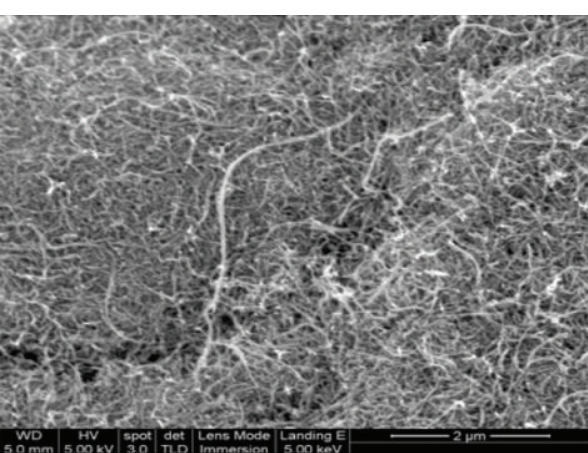

(b)
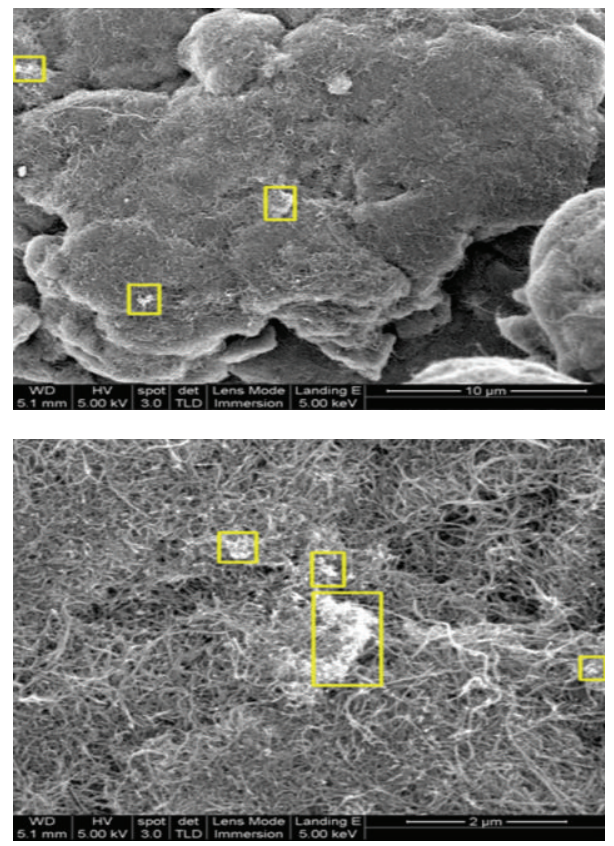

(c)

FIgURE 2: SEM images of (a) raw CNTs, (b) oxidized CNTs, and (c) CNTs-Fe 1 wt \% composite.

CNTs synthesis in FC-CVD. Table 2 shows a summary of the results of EDS analysis. By comparing between the results of unfunctionalized and functionalized CNTs, it is evident that the oxygen content in the functionalized CNT sample is higher than that of the raw CNTs which is attributed to the formation of carboxylic $(-\mathrm{COOH})$, hydroxyl $(-\mathrm{OH})$, and carbonyl $(-\mathrm{CHO})$ groups on the surface of CNTs during the oxidation process. The observed nickel content is due to its using as a catalyst during the CNTs synthesis. Iron content of CNTs impregnated with Fe was found to be $2.2 \%$ which is higher than the $1 \%$ Fe used. This may be attributed to the localized superficial analysis by EDS probe.

The study of the thermal degradation of materials is of major importance, since it can, in many cases, determine 
TABLE 2: EDS analysis of carbon nanotubes samples.

\begin{tabular}{|c|c|c|c|c|c|c|}
\hline \multirow{2}{*}{$\begin{array}{l}\text { CNT sample } \\
\text { Element }\end{array}$} & \multicolumn{2}{|c|}{ Raw CNTS } & \multicolumn{2}{|c|}{ Functionalized CNTS } & \multicolumn{2}{|c|}{ CNTS-nano Fe $1 \%$} \\
\hline & Weight $\%$ & Atomic \% & Weight \% & Atomic \% & Weight \% & Atomic \% \\
\hline $\mathrm{CK}$ & 94.42 & 96.99 & 85.44 & 89.40 & 87.70 & 91.60 \\
\hline $\mathrm{OK}$ & 3.28 & 2.53 & 13.09 & 10.28 & 10.08 & 7.91 \\
\hline Ni K & 2.31 & 0.48 & 1.48 & 0.32 & - & - \\
\hline Fe K & - & - & - & - & 2.22 & 0.50 \\
\hline Total \% & 100 & 100 & 100 & 100 & 100 & 100 \\
\hline
\end{tabular}

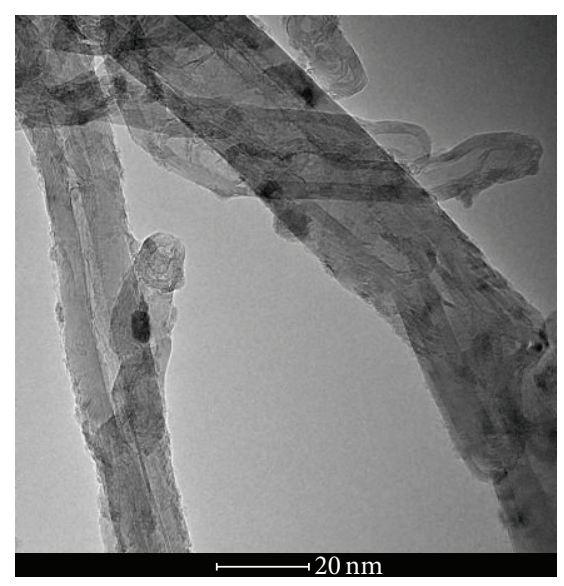

(a)

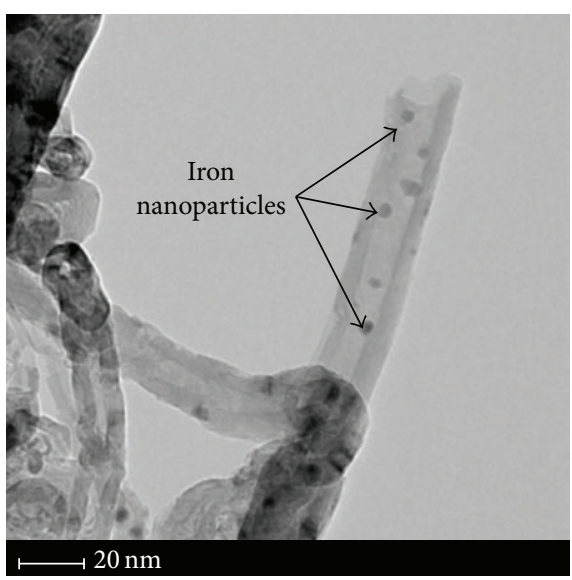

(b)

FIgURE 3: TEM images of (a) raw CNTSs and (b) CNTs-Fe wt 1\% composite showing iron nanoparticles.

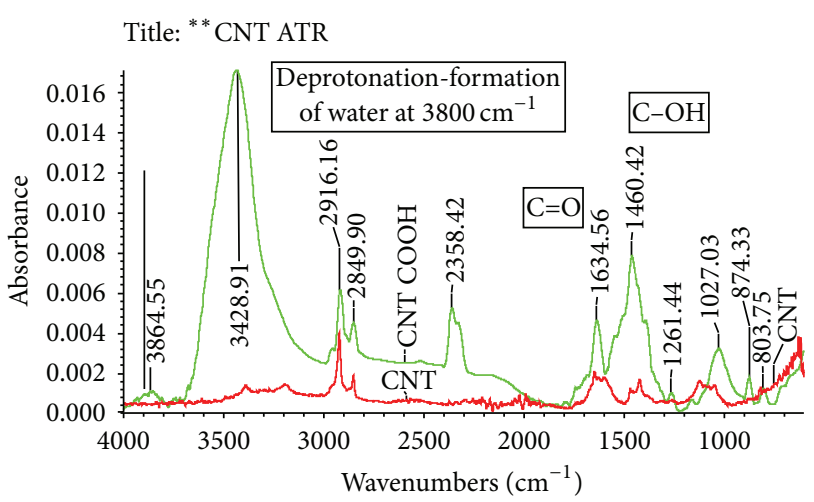

FIGURE 4: FTIR of raw (red) and functionalized CNTs (green).

the upper temperature limit of use for a material. In addition, considerable attention has been directed towards the exploitation of thermogravimetric data for the determination of functional groups. For this purpose, thermogravimetric analysis (TGA) is a technique widely used because of its simplicity and the information afforded by a simple thermogram. Figures 5(a) and 5(b) depict the TGA-DTG results for the carbon nanotubes functionalized with carboxylic function groups (CNT-COOH) and impregnated with iron nanoparticles (CNTs-Fe). The initial degradation of $\mathrm{COOH}$ which has been carried out in nitrogen condition starts at approximately $170^{\circ} \mathrm{C}$ and reaches a maximum weight loss of this acidic group at about $321^{\circ} \mathrm{C}$ and completes at about $480^{\circ} \mathrm{C}$ as revealed by the DTG curve. The second peak appearing at about $783^{\circ} \mathrm{C}$ corresponds to the oxidation of CNTs due to the decomposition of the carboxylic group releasing oxygen into the chamber of the TGA-DSC system. While for CNTs impregnated with iron nanoparticles, the initial oxidation temperatures start at $500^{\circ} \mathrm{C}$ followed by another oxidation state (second peak) starting at $525^{\circ} \mathrm{C}$ due to the variation in the size as shown in Figure 5(a).

\subsection{Adsorption Experiments}

3.2.1. Effect of $p H$. The $\mathrm{pH}$ of the aqueous solutions used in studying the adsorption phenomenon is considered as an important variable, which controls the adsorption of specific ions on the solid-water interfaces. The $\mathrm{pH}$ also plays an important role in the bromate removal mechanism which goes either through the bromate reduction or adsorption. When the $\mathrm{pH}$ of the solution is higher than the $\mathrm{pH}_{\mathrm{pzc}}$ of the adsorbent, the formed negative charge (-) on the surface provides better interactions which are favorable for adsorbing cationic species. The decrease of the $\mathrm{pH}$ leads to neutralization of the charge on the surface, and as $\mathrm{pH}$ value decreases below the $\mathrm{pH}_{\mathrm{pzc}}$ of the adsorbing materials, the positive charge density increases and adsorption capacity of anions increases. Therefore, bromate adsorption increases as the $\mathrm{pH}$ of the solution decreases to a value less than 6.6 of the raw CNTs and less than 3.1 for functionalized CNTs. 


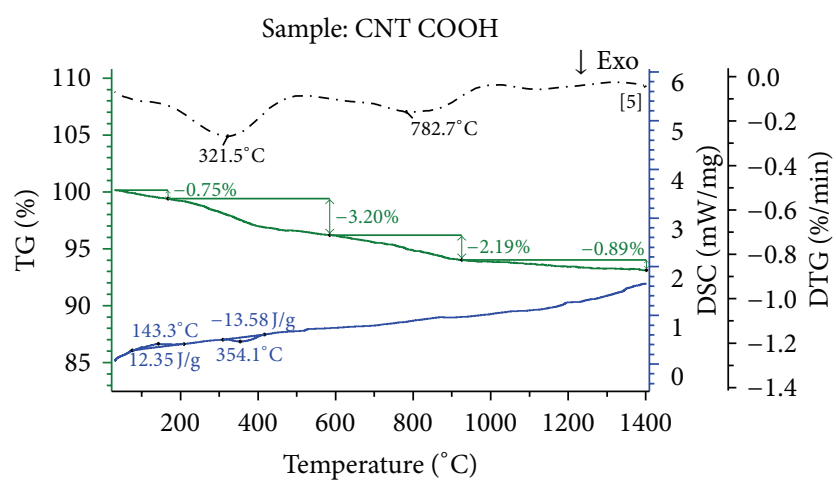

(a)

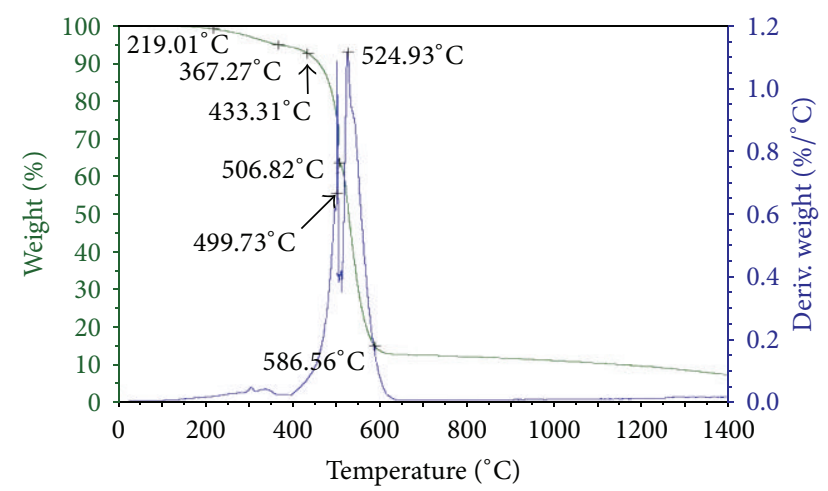

Universal V4.7A TA instruments

(b)

Figure 5: TGA-DSC results of (a) oxidized CNTs (TGA (green), DTG (black), DSC (BLUE)) and (b) CNTs-Fe 1\% composite (TGA (green), DTG (blue)).

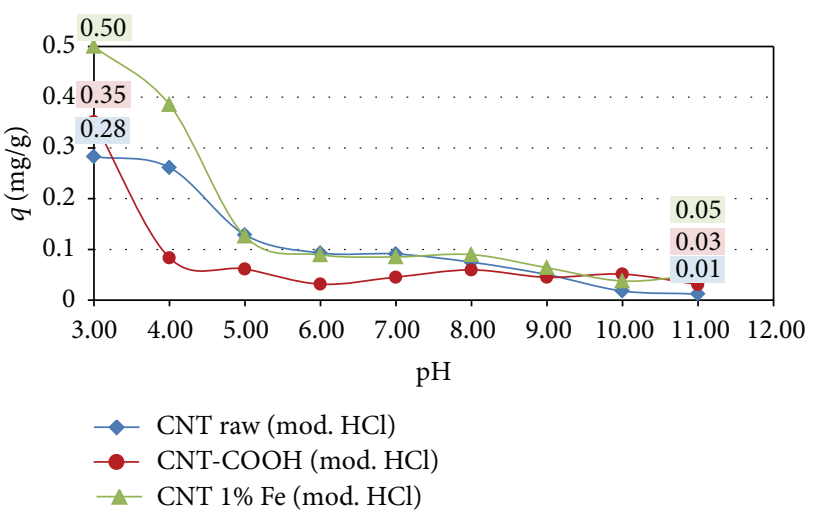

Figure 6: Bromate removal by different CNTs types versus $\mathrm{pH}$, $\mathrm{BrO}_{3}{ }^{-}$anion $0.5 \mathrm{mg} / \mathrm{L}$, contact time $24 \mathrm{~h}$, and agitation speed $150 \mathrm{rpm}$.

Figure 6 shows the adsorption capacity $(q)$ of CNTs versus solution $\mathrm{pH}$. On applying similar experimental conditions and varying only the $\mathrm{pH}$, the adsorption of bromate by CNTs was found to be higher than that of the functionalized CNTs at all $\mathrm{pH}$ values. This finding can be attributed to (1) the $\mathrm{pH}_{\mathrm{pzc}}$ of functionalized CNTs is lower than that of

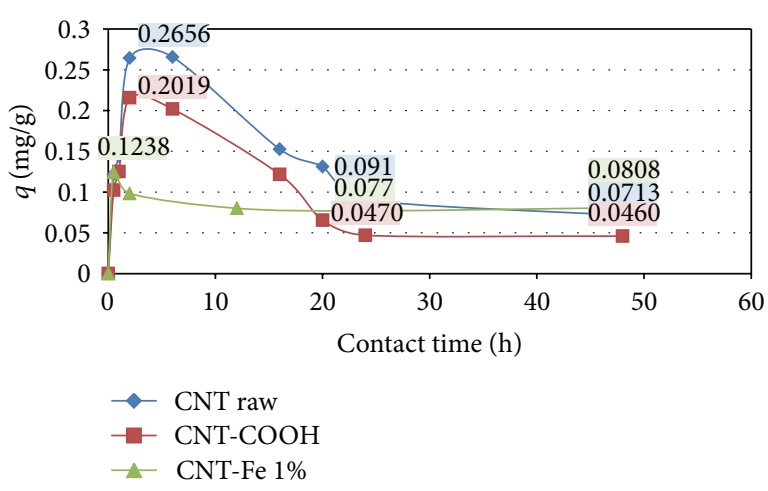

Figure 7: The effect of contact time for different CNTs types on bromate adsorption, speed $150 \mathrm{rpm}$, dose $50 \mathrm{mg}$, and $\mathrm{pH} 7.5$.

raw CNTS and (2) the carboxyl and the hydroxyl functional groups at the CNTs surface repel the $\mathrm{BrO}_{3}{ }^{-}$anion; hence, the adsorption capacity is reduced. In contrast, the adsorption capacities of CNTs-Fe 1\% are higher than that of raw CNTs in solutions of low $\mathrm{pH}$ values. This is because of the presence of the iron ions on the CNTs surface which will increase the density of the positive charges. However, the maximum adsorption capacities for raw CNTs, functionalized CNTs, and CNTs-Fe at $\mathrm{pH} 3.0$ were found to be $0.283,0.352$, $0.500 \mathrm{mg} / \mathrm{g}$, respectively and at a $\mathrm{pH}$ of 7.0 were $0.091,0.046$, and $0.0854 \mathrm{mg} / \mathrm{g}$, respectively, when $\mathrm{HCl}$ was used to adjust the $\mathrm{pH}$.

3.2.2. Effect of Contact Time. The effect of the contact time on the adsorption of bromate by the raw CNTs, the functionalized CNTs, and the CNTs-Fe $1 \%$ was investigated by keeping the CNTs dosage, the agitation speed, the $\mathrm{pH}$, and the initial bromate concentration constant. It was observed that the $\mathrm{BrO}_{3}{ }^{-}$anion adsorption shows positive results with contact time. The general adsorption mechanism is fast adsorption in the first contact time period and then desorption effect starts to be effective, as a result the adsorption capacity $(q)$ decreases until it reaches the equilibrium state. Figure 7 shows the adsorption capacity of the three CNTs types at different contact times when all other variables are constant. The maximum adsorption capacity was found to be $0.2656 \mathrm{mg} / \mathrm{g}$ achieved after 5 hours of contact for raw CNTs. The equilibrium adsorption capacities of raw CNTs, functionalized CNTs, and CNTs-Fe $1 \%$ achieved after 48 hours were 0.0713 , 0.0460 , and $0.0808 \mathrm{mg} / \mathrm{g}$, respectively.

3.2.3. Effect of the CNT Dosage. The batch adsorption experiments were carried out by using various amounts of raw CNTs, functionalized CNTs, and CNTs-Fe $1 \%$. For each of the adsorbents used, the added amounts ranged from 5 to $125 \mathrm{mg}$ at initial $\mathrm{pH}$ of 7.5, an agitation speed of $150 \mathrm{rpm}$, and a contact time of $24 \mathrm{~h}$. It was observed that even on increasing the amount of CNTs in the solution, the percentage removal of $\mathrm{BrO}_{3}{ }^{-}$anion remains almost constant $( \pm 5 \%)$. However, the overall adsorption capacity decreases since the $\mathrm{BrO}_{3}{ }^{-}$ anion concentration was constant but the CNTs dosage had 


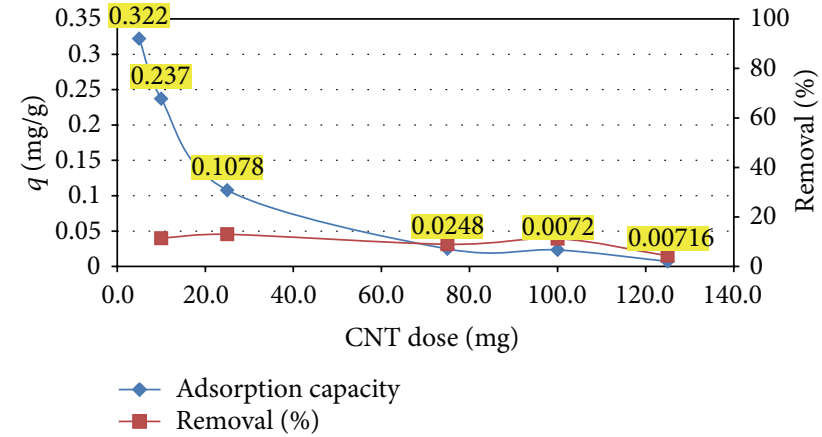

FIGURE 8: Bromate removal by raw CNTs at different dosages: $\mathrm{pH}$ $7.5, \mathrm{BrO}_{3}{ }^{-}$anion $0.5 \mathrm{mg} / \mathrm{L}$, contact time $24 \mathrm{~h}$, and agitation speed $150 \mathrm{rpm}$.

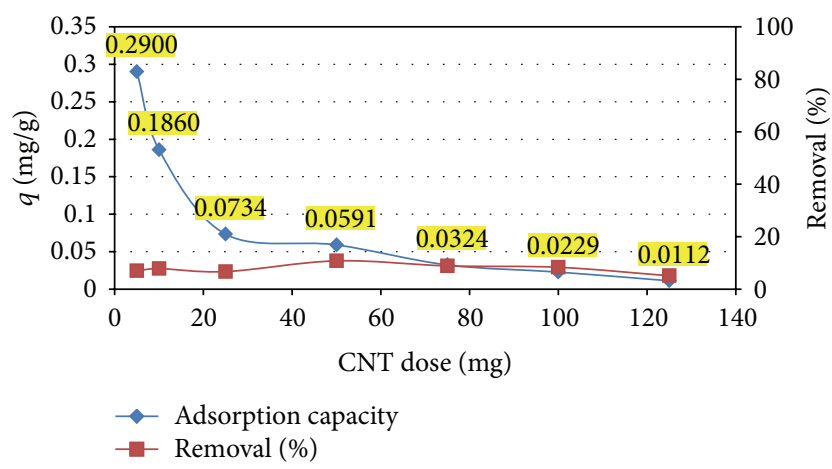

FIGURE 9: Bromate removal using functionalized CNTs at different dosages: $\mathrm{pH} 7.5, \mathrm{BrO}_{3}{ }^{-}$anion $0.5 \mathrm{mg} / \mathrm{L}$, contact time $24 \mathrm{~h}$, and agitation speed $150 \mathrm{rpm}$.

increased. The behavior of this nanomaterial is different from that of activated carbon (AC). In case of $\mathrm{AC}$, an increase in the dosage increases the removal percentage of $\mathrm{BrO}_{3}{ }^{-}$anion. This could be attributed to the bundling feature of CNTs in solutions which results in decreasing the open surface required for adsorption when more CNTs are introduced into the solution.

Figure 8 shows the adsorption capacity and the percentage removal of bromate by using raw CNTs. A maximum adsorption capacity of $0.322 \mathrm{mg} / \mathrm{g}$ was achieved by decreasing the amount of CNTs which will open the surface of the latter to adsorb $\mathrm{BrO}_{3}{ }^{-}$anion. The percentage removal was found to be less than $20 \%$ when the initial concentration of $\mathrm{BrO}_{3}{ }^{-}$ anion was $0.5 \mathrm{mg} / \mathrm{L}$.

Figure 9 shows the adsorption capacity and the percentage removal of $\mathrm{BrO}_{3}{ }^{-}$anion when functionalized CNTs were used. The maximum adsorption capacity obtained in case of functionalized CNTs was $0.290 \mathrm{mg} / \mathrm{g}$. On decreasing the amount of functionalized CNTs to $5 \mathrm{mg}$, more $\mathrm{BrO}_{3}{ }^{-}$anion is adsorbed due to more surface sites being accessible. The percentage removal was found to be less than $20 \%$ when the initial concentration of $\mathrm{BrO}_{3}{ }^{-}$anion was about $0.5 \mathrm{mg} / \mathrm{L}$.

Figure 10 shows the adsorption capacity when adsorbent was used. The maximum adsorption capacity was found to be $0.3460 \mathrm{mg} / \mathrm{g}$ when $5 \mathrm{mg}$ of CNTs-Fe dosage was used.

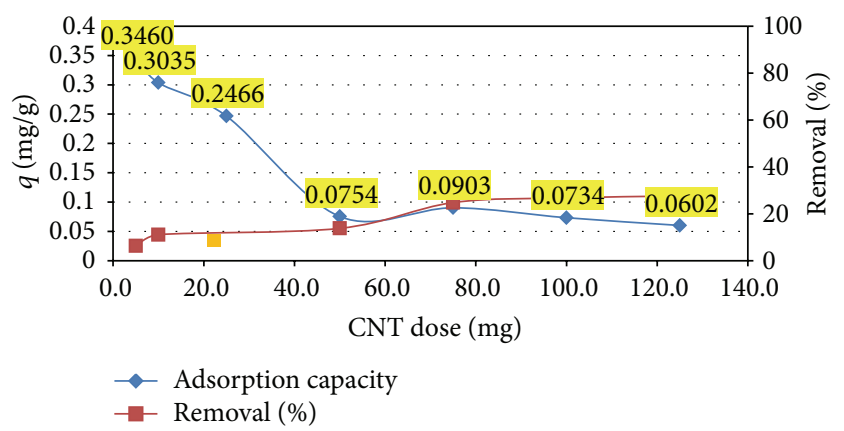

Figure 10: Bromate removal using CNTS-Fe at different dosages: $\mathrm{pH} 7.5, \mathrm{BrO}_{3}{ }^{-}$anion $0.5 \mathrm{mg} / \mathrm{L}$, contact time $24 \mathrm{~h}$, and agitation speed $150 \mathrm{rpm}$.

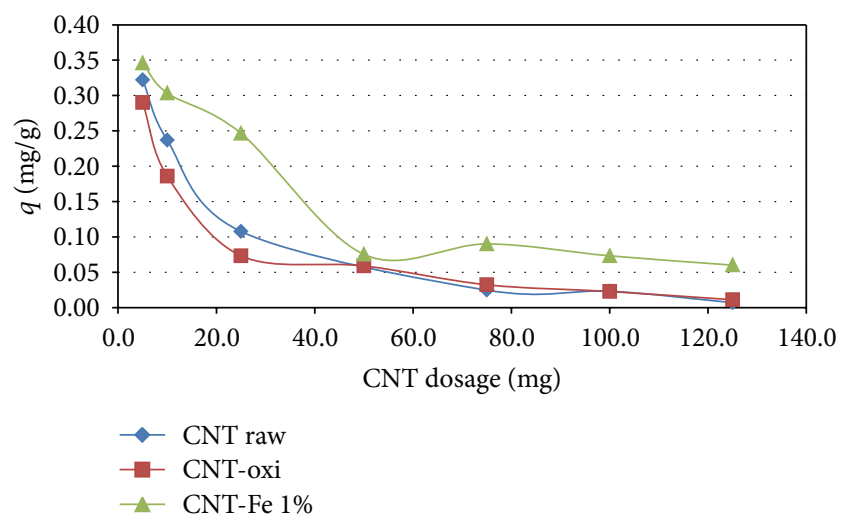

Figure 11: Bromate removal using different CNTs versus dosages: $\mathrm{pH} 7.5, \mathrm{BrO}_{3}{ }^{-}$anion $0.5 \mathrm{mg} / \mathrm{L}$, contact time $24 \mathrm{~h}$, and agitation speed $150 \mathrm{rpm}$.

The adsorption capacity of CNTs-Fe is higher than those obtained by the other types of CNTs; thus, this type has potential applications. Finally, Figure 11 shows the adsorption capacities for all types of CNTs used for the removal of $\mathrm{BrO}_{3}{ }^{-}$anion using different dosages. The highest adsorption capacity and best performance were obtained for CNTs-Fe composite and then for raw CNTs with adsorption capacities of 0.346 and $0.320 \mathrm{mg} / \mathrm{g}$, respectively.

3.2.4. Effect of Initial Concentration of Bromate. The effect of the initial concentration of $\mathrm{BrO}_{3}{ }^{-}$anion on the adsorption capacity of the CNTs was also investigated for raw CNTs. The adsorption capacity was found to increase with increasing $\mathrm{BrO}_{3}{ }^{-}$anion concentrations in the solution when all other variables were kept constant, $\mathrm{pH}$ 6.0, agitation speed $150 \mathrm{rpm}$, and CNTs dosage of $50 \mathrm{mg}$. This can be attributed to the fact that more $\mathrm{BrO}_{3}{ }^{-}$anions will be introduced to the CNTs surface; thus, the adsorption process is enhanced. Figure 12 shows the relationship between the adsorption capacity of raw CNTs and the initial concentration of $\mathrm{BrO}_{3}{ }^{-}$anion.

3.2.5. Effect of Coexisting Anions. The effect of other existing ions on the adsorption capacity was studied by using two different acids for the $\mathrm{pH}$ adjustment. Through using the two 


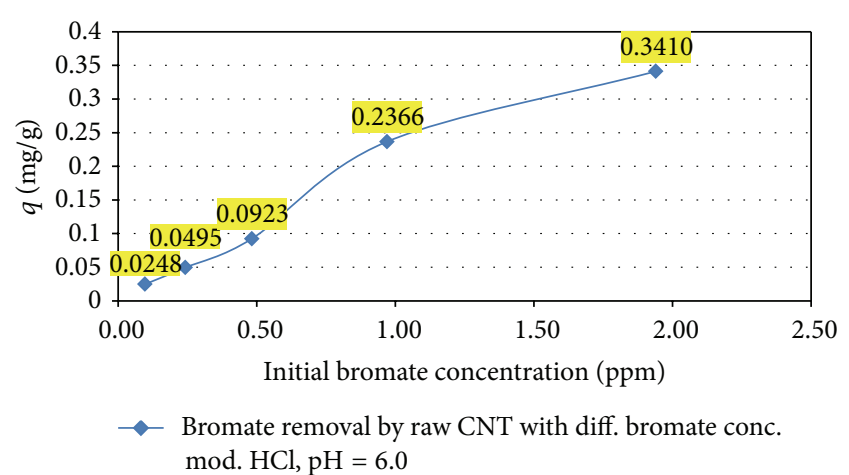

FIGURE 12: Adsorption capacity at different $\mathrm{BrO}_{3}{ }^{-}$anion concentrations: $\mathrm{pH}$ 6.0, dosage $50 \mathrm{mg}$, contact time $24 \mathrm{~h}$, and agitation speed $150 \mathrm{rpm}$.

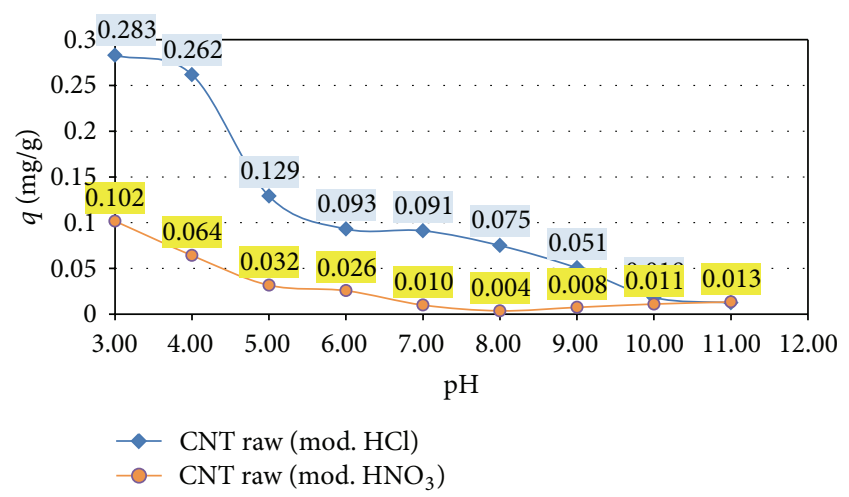

FIGURE 13: Bromate removal by raw CNTs modified by different acids versus $\mathrm{pH}$.

acids $\mathrm{HCl}$ and $\mathrm{HNO}_{3}$, each of a concentration of $0.1 \mathrm{M}$, the adsorption capacity of raw CNTs for $\mathrm{BrO}_{3}{ }^{-}$anion removal was studied as shown in Figure 13. The lower adsorption capacity of $\mathrm{BrO}_{3}{ }^{-}$anion in the presence of $\mathrm{NO}_{3}{ }^{-}$can be attributed to the competitive adsorption behavior between $\mathrm{BrO}_{3}{ }^{-}$anion and $\mathrm{NO}_{3}{ }^{-}$anions on the CNTs surface due to the fact that $\mathrm{NO}_{3}{ }^{-}$has a better affinity to be adsorbed more than $\mathrm{BrO}_{3}{ }^{-}$anion and could be attributed also to the smaller size of $\mathrm{NO}_{3}{ }^{-}$ion compared to $\mathrm{BrO}_{3}{ }^{-}$anion ion; hence, nitrate will be easily adsorbed at CNTs surface. However, the maximum adsorption capacities of raw CNTs (modified by $\mathrm{HCl}$ ) and raw $\mathrm{CNTs}$ (modified by $\mathrm{HNO}_{3}$ ) at $\mathrm{pH} 3.0$ were 0.283 and $0.102 \mathrm{mg} / \mathrm{g}$, respectively, and at $\mathrm{pH} 7.0$ were 0.091 and $0.010 \mathrm{mg} / \mathrm{g}$, respectively.

3.3. Adsorption Mechanism. In light of the above mentioned results, one can conclude that the proposed mechanism of $\mathrm{BrO}_{3}{ }^{-}$anion removal is adsorption. The charged surface of CNTs is attracting $\mathrm{BrO}_{3}{ }^{-}$anion in water by Van der Waals forces. This mechanism is rationally close to the proposed mechanism of $\mathrm{BrO}_{3}{ }^{-}$anion removal by AC except that no reduction was noted after the adsorption process. Figure 14 simulates the adsorption mechanism of $\mathrm{BrO}_{3}{ }^{-}$anion on the CNTs surface.

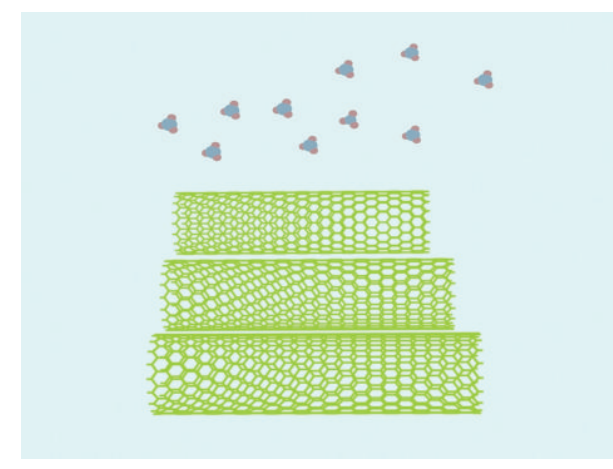

(a)

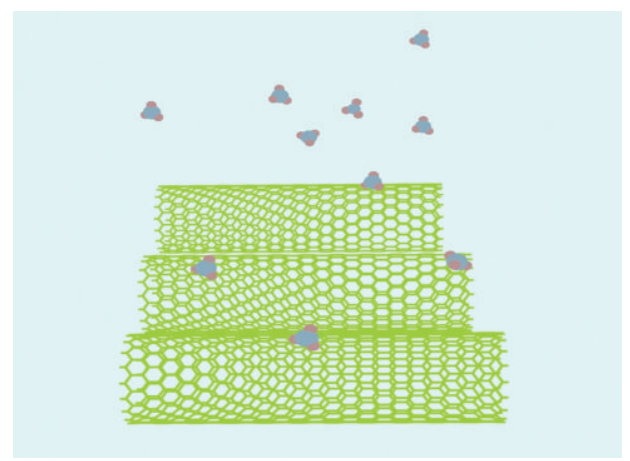

(b)

FIGURE 14: Bromate adsorption mechanism on raw CNTs (a) before adsorption and (b) after adsorption.

\section{Conclusion}

It can be concluded from the above mentioned results that the CNTs-Fe give higher adsorption capacity compared with the raw CNTs and the functionalized CNTs. It was found that it is better to use hydrochloric acid than nitric acid in order to adjust the $\mathrm{pH}$. This is due to the fact that nitrate ions will compete with the bromate when being adsorbed. It was also noted that the adsorption capacities of the three absorbents increase on decreasing the $\mathrm{pH}$ of the solution. Increasing the concentration of bromate has significantly increased the adsorption capacity. However, the adsorption capacity decreases on increasing the adsorbent dosage due to the bundling feature of the CNTs in solution.

\section{Conflict of Interests}

The authors declare that there is no conflict of interests regarding the publication of this paper.

\section{Acknowledgments}

The authors acknowledge the support of the Chemistry Department and the Chemical Engineering Department at King Fahd University. The authors highly appreciate the cooperation received from the Water Research Center in the Research Institute (RI) at King Fahd University of Petroleum and Minerals. 


\section{References}

[1] International Agency for Research on Cancer (IARC), Some Naturally Occurring and Synthetic Food Components, Furocoumarins and Ultraviolet Radiation, Lyon, France, 1999.

[2] United States Environmental Protection Agency (USEPA), "Toxicological review of bromate," Epa/635/R-01/002, United States Environmental Protection Agency, Washington, DC, USA, 2001.

[3] World Health Organization (WHO), "Bromate in drinking water. Background document for preparation of WHO guidelines for drinking-water quality," WHO/SDE/WSH/05.08/78, 2005.

[4] W. R. Haag and J. Holgne, "Ozonation of bromide-containing waters: kinetics of formation of hypobromous acid and bromate," Environmental Science \& Technology, vol. 17, no. 5, pp. 261-267, 1983.

[5] U. von Gunten and J. Hoigne, "Bromate formation during ozonation of bromide-containing waters: interaction of ozone and hydroxyl radical reactions," Environmental Science \& Technology, vol. 28, no. 7, pp. 1234-1242, 1994.

[6] U. Pinkernell and U. von Gunten, "Bromate minimization during ozonation: mechanistic considerations," Environmental Science \& Technology, vol. 35, no. 12, pp. 2525-2531, 2001.

[7] H.-S. Kim, H. Yamada, and H. Tsuno, "The removal of estrogenic activity and control of brominated by-products during ozonation of secondary effluents," Water Research, vol. 41, no. 7, pp. 1441-1446, 2007.

[8] H. S. Weinberg, C. A. Delcomyn, and V. Unnam, "Bromate in chlorinated drinking waters: occurrence and implications for future regulation," Environmental Science \& Technology, vol. 37, no. 14, pp. 3104-3110, 2003.

[9] L. Xie and C. Shang, "A review on bromate occurrence and removal strategies in water supply," Water Science and Technology, vol. 6, no. 6, pp. 131-136, 2006.

[10] M. S. Elovitz, U. von Gunten, and H.-P. Kaiser, "Hydroxyl radical/ozone ratios during ozonation processes. II. The effect of temperature, $\mathrm{pH}$, alkalinity, and DOM properties," Ozone: Science \& Engineering, vol. 22, no. 2, pp. 123-150, 2000.

[11] M. Asami, T. Aizawa, T. Morioka, W. Nishijima, A. Tabata, and Y. Magara, "Bromate removal during transition from new granular activated carbon (GAC) to biological activated carbon (BAC)," Water Research, vol. 33, no. 12, pp. 2797-2804, 1999.

[12] W. A. M. Hijnen, R. Voogt, H. R. Veenendaal, H. van der Jagt, and D. van der Kooij, "Bromate reduction by denitrifying bacteria," Applied and Environmental Microbiology, vol. 61, no. 1, pp. 239-244, 1995.

[13] A. Mills, A. Belghazi, and D. Rodman, "Bromate removal from drinking water by semiconductor photocatalysis," Water Research, vol. 30, no. 9, pp. 1973-1978, 1996.

[14] M. Siddiqui, W. Zhai, A. Gary, and C. Mysore, "Bromate ion removal by activated carbon," Water Research, vol. 30, no. 7, pp. 1651-1660, 1996.

[15] M. L. Bao, O. Griffini, D. Santianni, K. Barbieri, D. Burrini, and F. Pantani, "Removal of bromate ion from water using granular activated carbon," Water Research, vol. 33, no. 13, pp. 2959-2970, 1999.

[16] Q. Wang, S. Snyder, J. Kim, and H. Choi, "Aqueous ethanol modified nanoscale zerovalent iron in bromate reduction: synthesis, characterization, and reactivity," Environmental Science \& Technology, vol. 43, no. 9, pp. 3292-3299, 2009.
[17] W.-J. Huang and Y.-L. Cheng, "Effect of characteristics of activated carbon on removal of bromate," Separation and Purification Technology, vol. 59, no. 1, pp. 101-107, 2008.

[18] R. Sublet, M.-O. Simonnot, A. Boireau, and M. Sardin, "Selection of an adsorbent for lead removal from drinking water by a point-of-use treatment device," Water Research, vol. 37, no. 20, pp. 4904-4912, 2003.

[19] P. H. Andy, "Point of use removal of lead and copper in drinking water using hydroxylapatite and carbonate minerals," Patent Strom USA, Office UP, 1996.

[20] S. Kommineni, R. Narasimham, and H. Durbin, Point of Use/Point of Entry Treatment for Arsenic Removal: Operational Costs and Issues, Malcolm Pirnie, Phoenix, Ariz, USA, 2003.

[21] B. M. Thomson, T. J. Cotter, and J. D. Chwirka, "Design and operation of point-of-use treatment system for arsenic removal," Journal of Environmental Engineering, vol. 129, no. 6, pp. 561-564, 2003.

[22] P. C. Olsen and D. J. Paulson, Removal of Perfluorochemicals (PFC'S) with Point-of-Use Water Treatment Devices, Minnesota Department of Public Health, Minnesota, Minn, USA, 2008.

[23] N. Savage and M. S. Diallo, "Nanomaterials and water purification," Journal of Nanoparticle Research, vol. 7, no. 4-5, pp. 331342, 2005.

[24] Z.-C. Di, J. Ding, X.-J. Peng, Y.-H. Li, Z.-K. Luan, and J. Liang, "Chromium adsorption by aligned carbon nanotubes supported ceria nanoparticles," Chemosphere, vol. 62, no. 5, pp. 861-865, 2006.

[25] Y.-H. Li, Z. Di, J. Ding, D. Wu, Z. Luan, and Y. Zhu, "Adsorption thermodynamic, kinetic and desorption studies of $\mathrm{Pb}^{2+}$ on carbon nanotubes," Water Research, vol. 39, no. 4, pp. 605-609, 2005.

[26] G. P. Rao, C. Lu, and F. Su, "Sorption of divalent metal ions from aqueous solution by carbon nanotubes: a review," Separation and Purification Technology, vol. 58, no. 1, pp. 224-231, 2007.

[27] X. Peng, Z. Luan, J. Ding, Z. Di, Y. Li, and B. Tian, "Ceria nanoparticles supported on carbon nanotubes for the removal of arsenate from water," Materials Letters, vol. 59, no. 4, pp. 399403, 2005.

[28] S. Gotovac, C.-M. Yang, Y. Hattori, K. Takahashi, H. Kanoh, and K. Kaneko, "Adsorption of polyaromatic hydrocarbons on single wall carbon nanotubes of different functionalities and diameters," Journal of Colloid and Interface Science, vol. 314, no. 1, pp. 18-24, 2007.

[29] T. G. Hedderman, S. M. Keogh, G. Chambers, and H. J. Byrne, "In-depth study into the interaction of single walled carbon nanotubes with anthracene and p-terphenyl," Journal of Physical Chemistry B, vol. 110, no. 9, pp. 3895-3901, 2006.

[30] K. Yang, L. Zhu, and B. Xing, "Adsorption of polycyclic aromatic hydrocarbons by carbon nanomaterials," Environmental Science \& Technology, vol. 40, no. 6, pp. 1855-1861, 2006.

[31] X. M. Yan, B. Y. Shi, J. J. Lu, C. H. Feng, D. S. Wang, and H. X. Tang, "Adsorption and desorption of atrazine on carbon nanotubes," Journal of Colloid and Interface Science, vol. 321, no. 1, pp. 30-38, 2008.

[32] M. A. Atieh, M. B. Fettouhi, A. B. Al-Mammum, and N. B. Yahya, "Lead removal by using carbon nanotubes," International Journal of Nanoparticles, vol. 2, no. 1-6, pp. 329-338, 2009.

[33] M. A. Atieh, O. Y. Bakather, B. S. Tawabini et al., "Removal of chromium (III) from water by using modified and nonmodified carbon nanotubes," Journal of Nanomaterials, vol. 2010, Article ID 232378, 9 pages, 2010. 

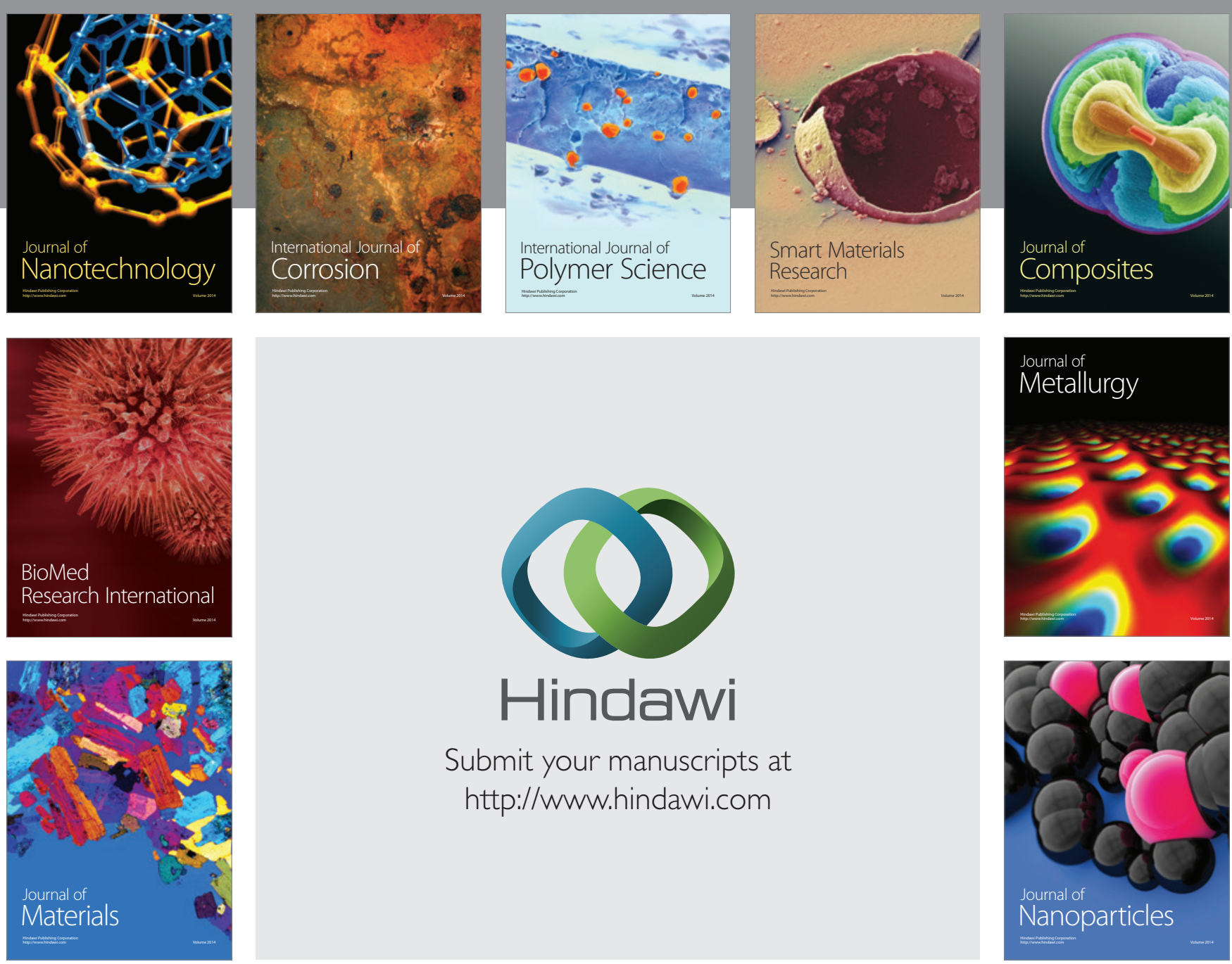

Submit your manuscripts at http://www.hindawi.com
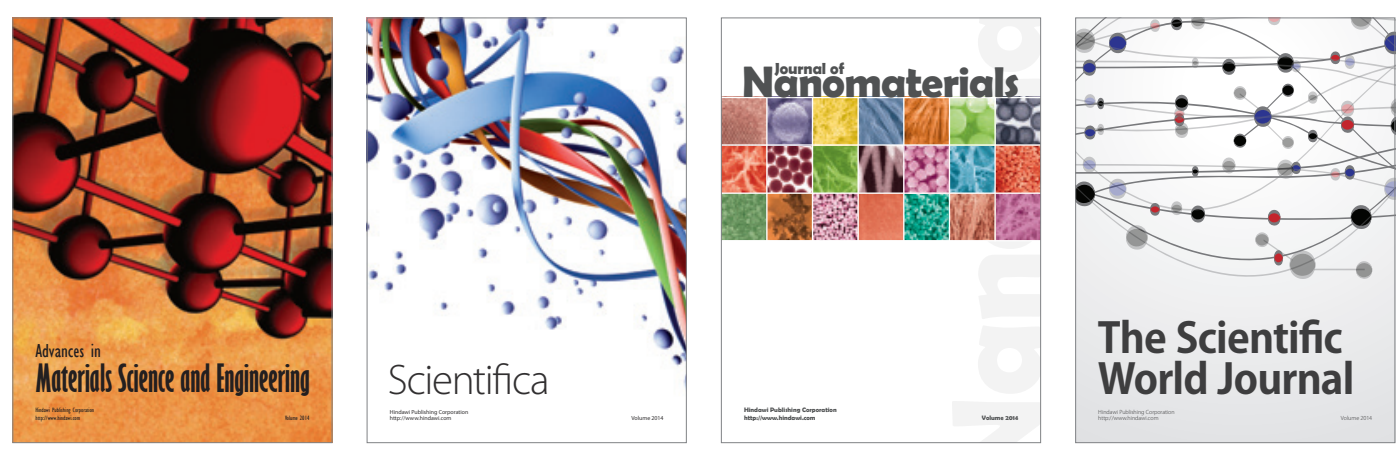

\section{The Scientific World Journal}
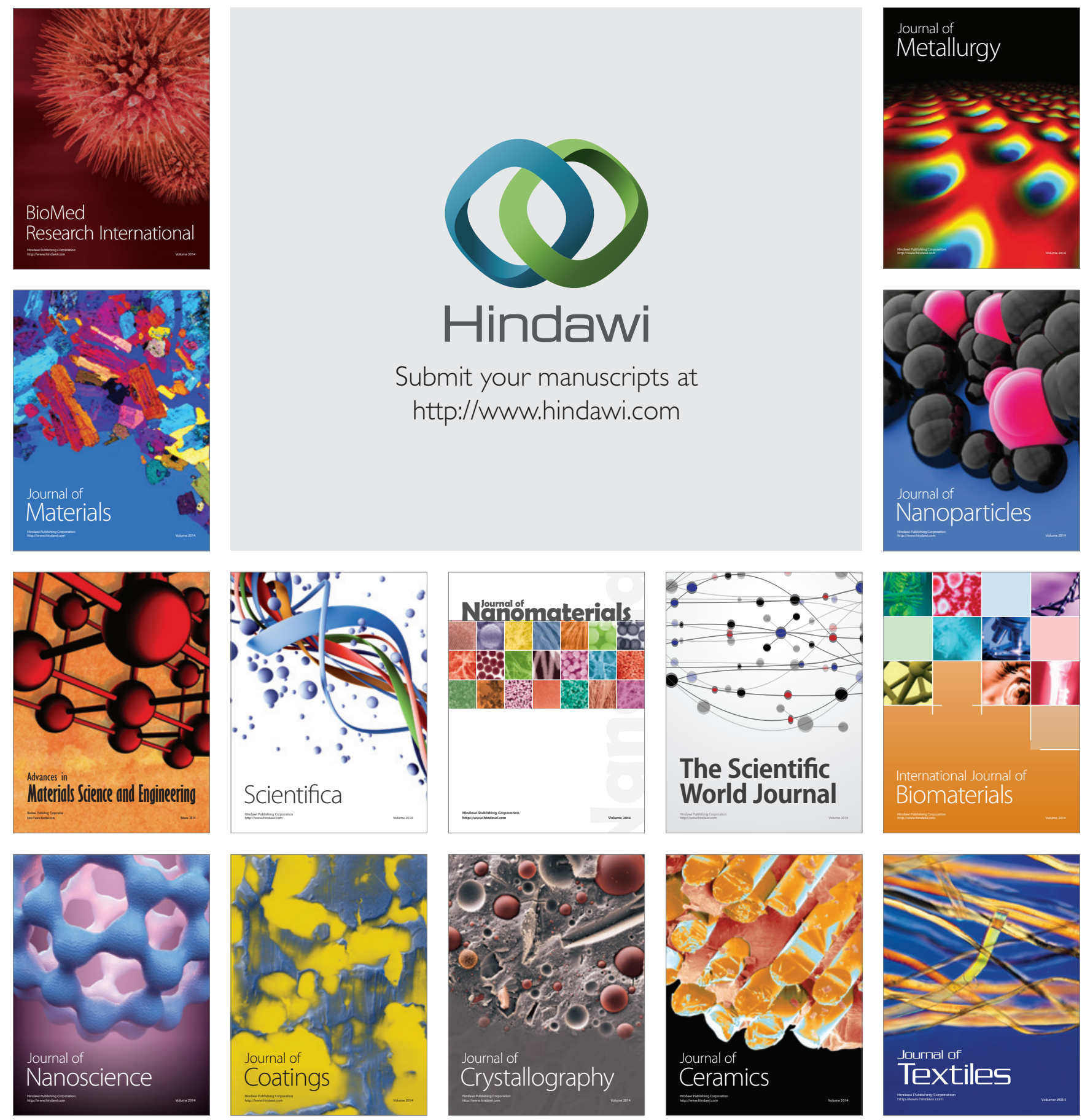